\title{
Penentuan Sub-sub Daerah Aliran Stratified Udara-Air pada Pipa Horisontal Menggunakan Constant Electric Current Method (CECM)
}

\author{
Akhmad Zidni Hudaya \\ Dosen Fakultas Teknik, Program Studi Teknik Mesin \\ Universitas Muria Kudus. \\ Email : zidni01@yahoo.com \\ Indarto \\ Jurusan Teknik Mesin dan Industri, Universitas Gadjah Mada. \\ Jl. Grafika No. 2 Kompleks UGM, Yogyakarta 55281, Indonesia. \\ Deendarlianto \\ Jurusan Teknik Mesin dan Industri, Universitas Gadjah Mada. \\ Jl. Grafika No. 2 Kompleks UGM, Yogyakarta 55281, Indonesia.
}

\begin{abstract}
ABSTRAK
Visualisasi dan liquid hold-up aliran stratified udara-air pada pipa horizontal sebagai fungsi waktu (dia. dalam pipa 26,0 $\mathrm{mm}$ dan total panjang seksi uji 9,5 m) telah diteliti secara eksperimental. Pada penelitian ini, studi visualisasi dilakukan dari analisa data visual yang dihasilkan kamera video kecepatan tinggi dan perilaku tebal film aliran diteliti dengan mengukur liquid hold-up menggunakan Constant Electric Current Method (CECM). Prinsip dari metode ini didasarkan atas perbedaan konduktivitas pada cairan dan gas. Pada penelitian ini digunakan sensor CECM sebanyak 3 buah dengan jarak aksial antar sensor $215 \mathrm{~mm}$. Hasil penelitian ini menunjukkan bahwa karakteristik gelombang antarmuka yang dihasilkan dari pemprosesan sinyal CECM dan studi visual dapat digunakan untuk menentukan sub-sub daerah aliran stratified. Peta pola aliran stratified Udara-Air pada Pipa Horisontal yang dihasilkan dari penelitian ini dipresentasikan dan dibandingkan dengan petapeta yang ada dari penelitian-penelitian terdahulu.
\end{abstract}

Kata Kunci : Sub-sub daerah aliran, aliran stratified, $C E C M$, gelombang antarmuka

\begin{abstract}
The visualitation and the time variation of liquid hold-up in a horizontal air-water stratified flow $(26.0 \mathrm{~mm} \mathrm{ID}$ and $9.5 \mathrm{~m}$ in total length) has been investigated experimentally. In the present experimental study, the visualisation study was carried-out from the analizing of the visual data obatined from the video camera and the liquid film behavior was investigated by measure the instantaneous local liquid hold-up by using a Constant Electric Current Method (CECM). The principle of this method is on the basis of the conductivity ratio of the two-phase components. Here we used three pairs of liquid hold-up sensors arranged with an axial spacing of $215 \mathrm{~mm}$. As a result it was found that : Both the visual and the signal characterization of the interfacial wave can be used to determine the flow sub-regime in air-water stratified flow. A flow pattern map for horzontal air-water stratified flow is was presented and compared with the maps available from the literature.
\end{abstract}

Keywords: flow sub-regimes, stratified flow, CECM, interfacial wave

\section{PENDAHULUAN}

Pola aliran stratified merupakan pola aliran dua fasa yang mempunyai tingkat keamanan operasional yang tinggi. Pembahasan mengenai antarmuka aliran stratified gas-cairan telah menjadi topik yang menarik sejak puluhan tahun. Pada aliran stratified fasa cairan dan fasa gas terpisah secara jelas oleh 
adanya perbedaan berat jenis antara kedua fasa. Beberapa peta pola aliran untuk sistem air-udara dalam literatur seperti peta Baker (1954), Mandhane (1974), Taitel dan Dukler (1976) Lin dan Hanratty (1987) memperlihatkan adanya daerah pola aliran stratified dan transisi pola aliran strtified ke pola aliran yang lain. Meskipun terdapat banyak struktur antarmuka yang komplek pada aliran stratified, peta-peta pola aliran biasanya pola aliran stratified dibagi menjadi dua sub daerah yaitu stratified smooth dan stratified wavy. Hal ini sangat menarik untuk dibahas karena bentuk struktur antarmuka pada aliran menggambarkan pola aliran yang terjadi dan perubahan pola aliran yang lebih detail dari aliran stratified dapat diprediksi dengan pengamatan pada struktur antar mukanya.

Taitel dan Dukler (1976), menggunakan beberapa pendekatan untuk menjelaskan mekanisme transisi dari stratified smooth ke stratified wavy. Taitel dan Dukler (1976) mengusulkan suatu korelasi untuk kecepatan kritis pada saat terjadinya permulaan ketidakstabilan antarmuka yang menyebabkan pembangkitan gelombang. Lin dan Hanratty (1986), menjelaskan transisi pada aliran stratified menggunakan teori stabilitas linier dengan memasukkan faktor viscous dan inersia. Spedding dan Nguyen (1979) secara detail mengamati aliran stratified dan gelombang-gelombang lain yang terbentuk pada permukaan akibat perubahan kecepatan gas pada pipa horizontal secara visual. Kelemahan dari metode pengamatan visual ini adalah pengamatan visual dapat dilakukan pada kondisi kecepatan gas rendah, akan tetapi pada kecepatan gas yang tinggi morfologi aliran menjadi sulit diamati. Spedding dan Spence (1993) menggunakan kombinasi pengamatan visual dan karakteristik fluktuasi tekanan dan liquid hold-up rata-rata untuk menentukan transisi gelombang. Model-model teori dan empiris yang dihasilkan oleh Spedding dan Spence (1993) tidak memuaskan dalam memprediksi batas transisi fasa jika parameter geometri dan propertis fisik dari fluida divariasi. Sehingga dibutuhkan pengembangan metode lain yang bagus untuk memprediksi transisi pola aliran.

Selain metode pengamatan visual, analisa sinyal liquid hold-up merupakan salah satu metode untuk menentukan pola dan karakteristik aliran dua fasa. Sedangkan pengukuran liquid hold-up sebagai fungsi waktu masih menjadi permasalahan yang belum tuntas dalam permasalahan-permasalahan aliran dua fasa di Indonesia. Pengukuran liquid hold-up sebagai fungsi waktu umumnya menggunakan metode konduktansi. Salah satu metode konduktansi yang dikembangkan oleh Fukano (1989) adalah Constant Electric Current Method (CECM). Karakteritik dari CECM adalah sumber tenaga arus konstan digunakan untuk memberi tenaga listrik pada dua buah elektroda. Satu digunakan untuk memberi tenaga listrik dan yang lain untuk mendeteksi informasi ketebalan film. Keutamaan CECM adalah keluaran elektroda sensor tidak tergantung pada lokasi fase gas, sensivitas mendeteksi perubahan hold up lebih tinggi, dan interaksi diantara kedua elektroda diabaikan.

Dari uraian di atas dan melihat pentingnya pengetahuan mendetail tentang aliran stratified, serta belum banyak dijumpainya data base, maka perlu dilakukan penelitian yang komprehensif untuk mengetahui sub-sub daerah pada pola aliran stratified udara-air pada pipa horizontal berdasarkan analisa sinyal liquid hold-up dengan Constant Electric Current Method (CECM).

\section{METODA PENELITIAN}

Pada penelitian ini pipa acrylic transparan ID $26 \mathrm{~mm}$ digunakan agar perilaku aliran dapat diamati. Panjang pipa sebelum seksi uji didesain $5 \mathrm{~m}$ agar menjamin aliran berkembang penuh. Panjang pipa seksi uji untuk visualisasi $1 \mathrm{~m}$ dan untuk liquid hold-up $1,72 \mathrm{~m}$. Untuk mengukur liquid hold-up digunakan sensor CECM sebanyak 3 buah dengan jarak radial antar sensor $215 \mathrm{~mm}$ guna menjamin sensor dapat membaca panjang gelombang. Sensor CECM terdiri dari sepasang elektroda kuningan dengan tebal $1 \mathrm{~mm}$ dan jarak antar elektroda $5 \mathrm{~mm}$. Pada ujung-ujung seksi uji dipasang elektroda yang berfungsi untuk mengalirkan arus listrik konstan yang berasal dari power suplai. Sinyal liquid hold-up dari sensor dikuatkan dengan amplifier, kemudian diubah oleh Analog to Digital Converter (ADC) agar dapat dibaca oleh komputer.

Prinsip kerja dari CECM didasarkan atas perbedaan tahanan pada cairan dan gas. Tahanan listrik aliran dua fasa, $\mathrm{R}_{\mathrm{TP}}$, dalam unit panjang dari saluran diekspresikan pada persamaan 1 . 


$$
\frac{1}{R_{T P}}=\frac{1-M_{T}}{B_{E}}+\frac{1}{R_{L}}
$$

Dimana $\mathrm{R}_{\mathrm{G}}$ dan $\mathrm{R}_{\mathrm{L}}$ adalah tahanan listrik fase gas dan liquid yang masing-masing menempati bidang potongan pipa. Liquid hold-up $(\eta)$ diekspresikan dalam unit panjang $\left(\mathrm{V}_{\mathrm{TP}}\right)$ pada saat arus konstan $\mathrm{I}_{0}$ dicatukan. Hold-up diekspresikan oleh persamaan 2, dan untuk kasus aliran dua fasa udara-air, nilai $\mathrm{R}_{\mathrm{G}} \gg \mathrm{R}_{\mathrm{L}}$.

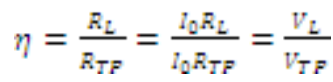

Dimana $\mathrm{V}_{\mathrm{L}}$ adalah drop tegangan saat liquid yang mengalir menempati sejumlah area dari pipa. Jika tahanan listrik dan drop tegangan berturut-turut sebagai $\mathrm{R}_{\mathrm{TP} 0}$ dan $\mathrm{V}_{\mathrm{TP} 0}$ saat hold-up diketahui nilainya, $\eta_{0}$ dan arus listrik $I_{0}$ pada nilai yang sama dengan persamaan 2 , maka $\eta_{0}$ pada persamaan 3 didapatkan dari persamaan 2 .

$$
\eta_{0}=\frac{\mathbb{L}_{\mathrm{D}} R_{L}}{\mathbb{U}_{\mathrm{D}} R_{T F D}}=\frac{\mathbb{V}_{L}}{V_{T F D}}
$$

Dengan mengeliminasi $\mathrm{V}_{\mathrm{L}}$ pada dua persamaan 3, maka diperoleh nilai hold-up seperti pada persamaan 4.

$$
\eta=\frac{\pi_{D} R_{T F Q}}{\pi_{D} R_{L}} \eta_{0}=\frac{V_{T F Q}}{W_{T F}} \eta_{0}
$$

Jika $\mathrm{V}_{\mathrm{TP}}$ diukur dibawah kondisi dari nilai yang diketahui $\left(\eta_{0}, \mathrm{~V}_{\mathrm{L}}\right.$ atau $\left.\mathrm{V}_{\mathrm{TP} 0}\right)$ maka kita dapat menentukan hold-up ( $\eta$ ).

Pada analisa sinyal, sinyal rangkaian waktu yang dikumpulkan dianalisa secara statistik / stochastic untuk diinginkan.

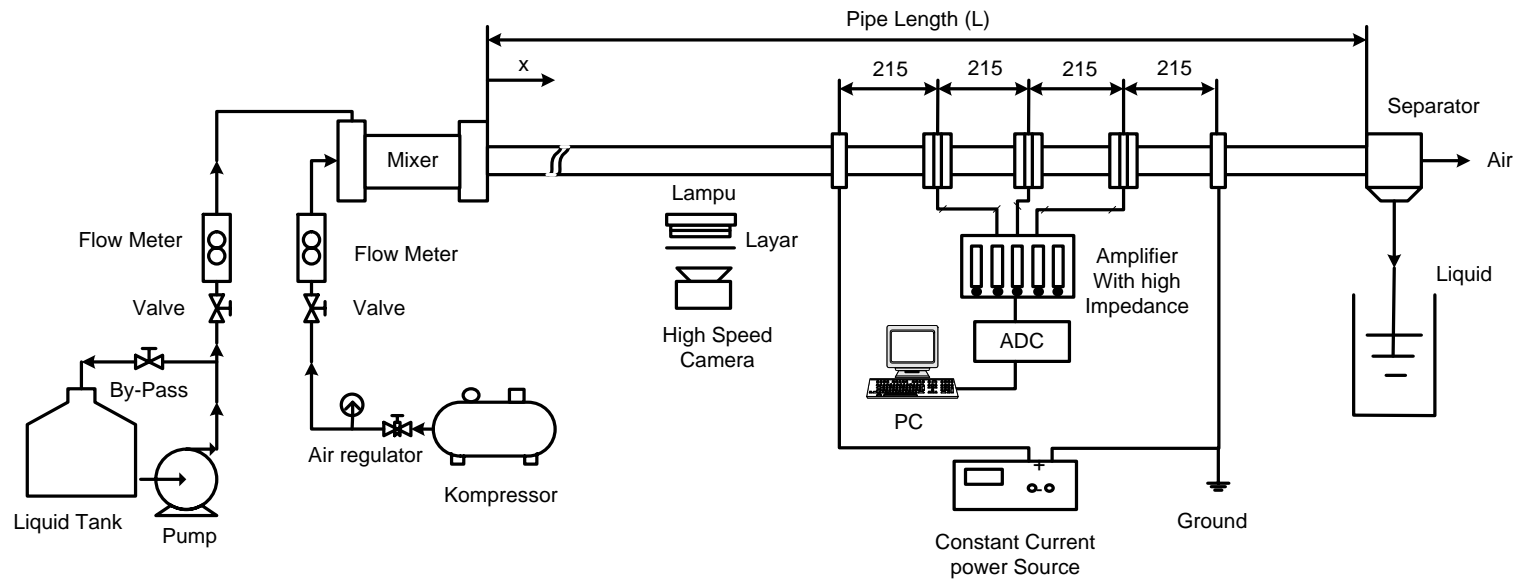

\section{Gambar 1. Skema Diagram Peralatan}

\section{HASIL DAN PEMBAHASAN}

\subsection{Karakterisasi Pola Aliran}

Bentuk struktur antar muka aliran stratified pada penelitian ini diamati dengan dua cara yaitu secara visual dan analisa sinyal. Metode ini lebih obyektif dalam menentukan sub-sub daerah pada aliran stratified dibanding dengan pengamatan secara visual saja. Berdasarkan pada pengamatan visual, data hasil rekaman video dan data liquid hold-up sebagai fungsi waktu dari penelitian yang telah dilakukan, 
Pola aliran stratified dari hasil variasi kecepatan superfisial air dan udara yang digunakan dapat dikelompokkan menjadi stratified smooth (SS), stratified wavy + ripple (SR), Stratified wavy + Roll $(S R W)$, dan Pseudo-slug (PS). Karakteristik dari pola-pola aliran ini dapat dijelaskan sebagai berikut :

a. Stratified Smooth (SS)

Pola aliran stratified mempunyai ciri bahwa fluida cair dan gas terpisah secara jelas karena adanya perbedaan berat jenis. Sedangkan pola aliran stratified smooth terjadi pada kecepatan superfisial cairan dan gas yang rendah sehingga interface dari cairan dan gas halus (smooth) seperti yang terlihat pada gambar 2 .

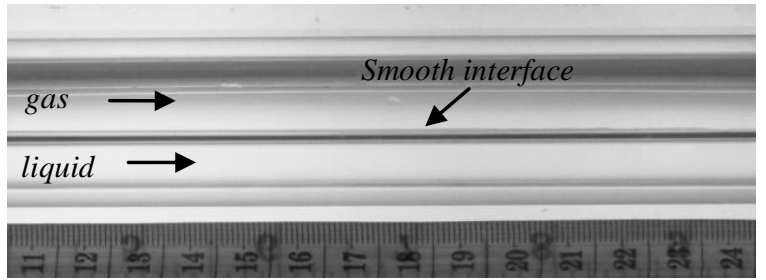

Gambar 2. Contoh Visualisasi Aliran Stratified Smooth $\left(\mathrm{J}_{\mathrm{L}}=0,016 \mathrm{~m} / \mathrm{s}\right.$ dan $\left.\mathbf{J}_{\mathrm{G}}=\mathbf{1 , 0 2} \mathrm{m} / \mathrm{s}\right)$

Pola aliran stratified smooth dapat juga dilihat dari karakteristik transien liquid hold-up seperti terlihat pada gambar 3. Pada Gambar 3. terlihat bahwa data sinyal liquid hold-up tampak seperti garis lurus dan tidak terlihat adanya fluktuasi yang signifikan.

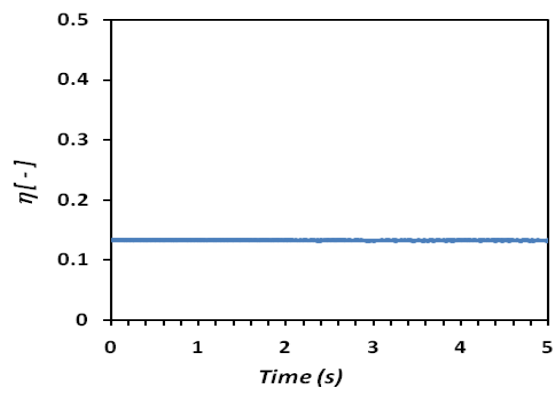

\section{Gambar 3. Contoh Liquid hold- up Aliran Stratified Smooth $\left(\mathrm{J}_{\mathrm{L}}=0,016 \mathrm{~m} / \mathrm{s}\right.$ dan $\left.\mathbf{J}_{\mathbf{G}}=\mathbf{1 , 0 2} \mathbf{m} / \mathbf{s}\right)$}

Gambar 4. merupakan karakteristik probability distribution function (PDF) aliran stratified smooth $\left(\mathrm{J}_{\mathrm{L}}=0,016 \mathrm{~m} / \mathrm{s}\right.$ dan $\left.\mathrm{J}_{\mathrm{G}}=1,02 \mathrm{~m} / \mathrm{s}\right)$. Pada gambar 4. terlihat bahwa karakteristik PDF menunjukkan kelas data yang mengumpul membentuk dua kelas data.

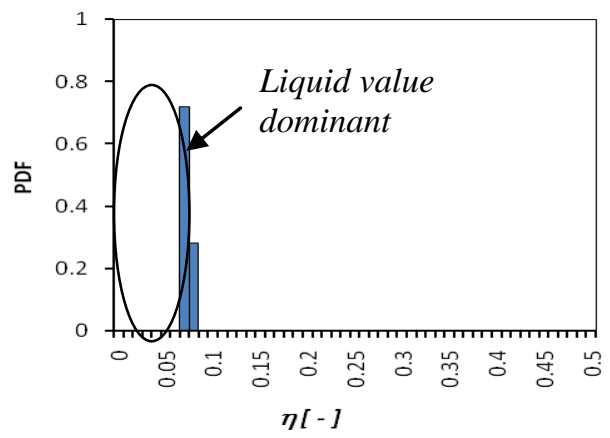

Gambar 4. Contoh PDF Aliran Stratified Smooth $\left(\mathrm{J}_{\mathrm{L}}=0,016 \mathrm{~m} / \mathrm{s}\right.$ dan $\left.\mathbf{J}_{\mathrm{G}}=1,02 \mathrm{~m} / \mathrm{s}\right)$ 
b. $\quad$ Stratified Wavy + Ripple (SR)

Pola aliran ini terbentuk sejalan dengan penambahan kecepatan superfisial udara dan atau kecepatan superfisial air. Pada kondisi ini riak-riak gelombang mulai terbentuk sehingga topologi pola alirannya akan berubah dari stratified smooth menjadi stratifed wavy+ripple seperti yang terlihat pada gambar 5 .

Pada penambahan kecepatan superfisial air yang lebih tinggi lagi dimana pada kondisi ini selain terdapat riak-riak gelombang (ripple), akan tampak juga gelombang panjang sehingga topologi pola aliran akan sedikit berubah akan tetapi masih dalam daerah stratifed wavy+ripple.

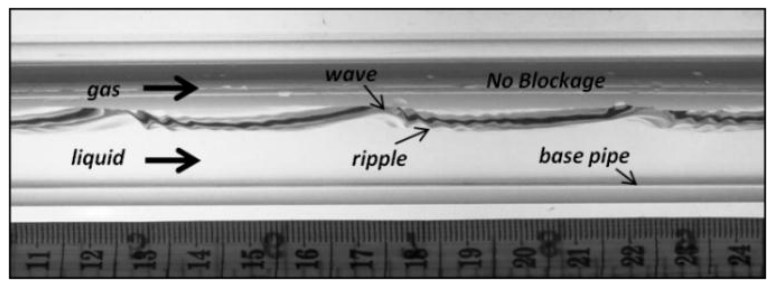

Gambar 5. Visualisasi Aliran Stratified Wavy + Ripple $\left(\mathbf{J}_{\mathrm{L}}=0,092 \mathrm{~m} / \mathrm{s}\right.$ dan $\left.\mathbf{J}_{\mathrm{G}}=1,02 \mathrm{~m} / \mathrm{s}\right)$

Pola aliran stratified + ripple dapat juga dilihat dari karakteristik transien liquid hold-up seperti terlihat pada gambar 6 .

Gambar 7. merupakan karakteristik probability distribution function (PDF) aliran stratified wavy + ripple $\left(\mathrm{J}_{\mathrm{L}}=0,092 \mathrm{~m} / \mathrm{s}\right.$ dan $\left.\mathrm{J}_{\mathrm{G}}=1,02 \mathrm{~m} / \mathrm{s}\right)$. Pada gambar 7 terlihat bahwa karakteristik PDF mempunyai kelas data yang lebih menyebar dibandingkan dengan karakteristik PDF stratified smooth.

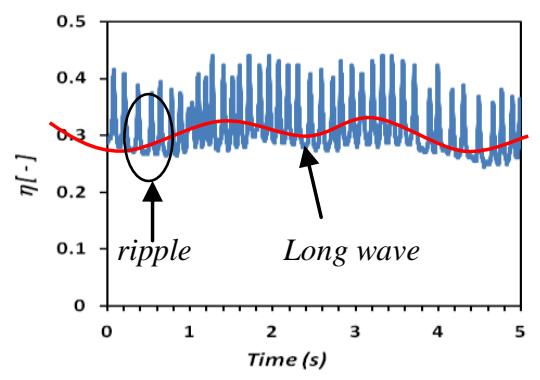

Gambar 6. Liquid Hold-Up Aliran Stratified Wavy + Ripple $\left(\mathrm{J}_{\mathrm{L}}=0,092 \mathrm{~m} / \mathrm{s}\right.$ dan $\left.\mathrm{J}_{\mathrm{G}}=1,02 \mathrm{~m} / \mathrm{s}\right)$

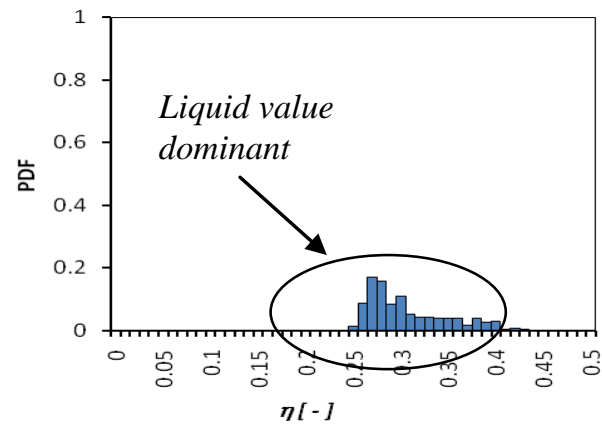

Gambar 7. Contoh PDF Aliran Stratified Wavy + Ripple $\left(\mathrm{J}_{\mathrm{L}}=0,092 \mathrm{~m} / \mathrm{s}\right.$ dan $\left.\mathrm{J}_{\mathrm{G}}=1,02 \mathrm{~m} / \mathrm{s}\right)$ 
c. Stratified Wavy + Roll (SRW)

Pola aliran ini terbentuk sejalan dengan penambahan kecepatan superfisial udara dan air yang cukup signifikan dimana pada kondisi ini akan terbentuk gulungan-gulungan (roll) sehingga topologi pola aliran akan berubah menjadi stratifed wavy + roll seperti terlihat pada gambar 8 . Pada gambar 8. terlihat bahwa gulungan-gulungan yang terjadi pada kondisi ini akan menyebabkan fluktuasi liquid hold-up menjadi lebih besar.

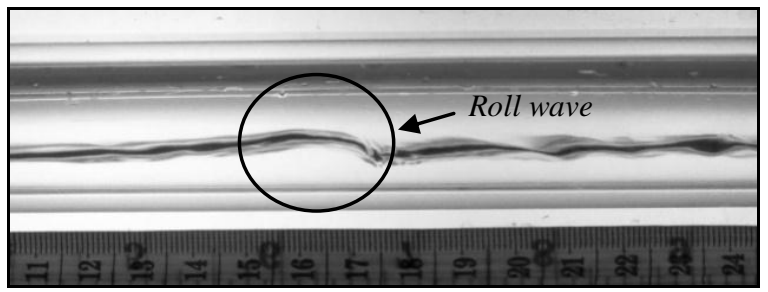

Gambar 8. Contoh Visualisasi Aliran Stratified Wavy + Roll $\left(\mathrm{J}_{\mathrm{L}}=0,047 \mathrm{~m} / \mathrm{s}\right.$ dan $\left.\mathbf{J}_{\mathrm{G}}=3.77 \mathrm{~m} / \mathrm{s}\right)$

Pola aliran stratified + roll dapat juga dilihat dari karakteristik transien liquid hold-up seperti terlihat pada gambar 9. Sedangkan gambar 10. merupakan karakteristik probability distribution function (PDF) aliran stratified wavy $+\operatorname{roll}\left(\mathrm{J}_{\mathrm{L}}=0,047 \mathrm{~m} / \mathrm{s}\right.$ dan $\left.\mathrm{J}_{\mathrm{G}}=3.77 \mathrm{~m} / \mathrm{s}\right)$

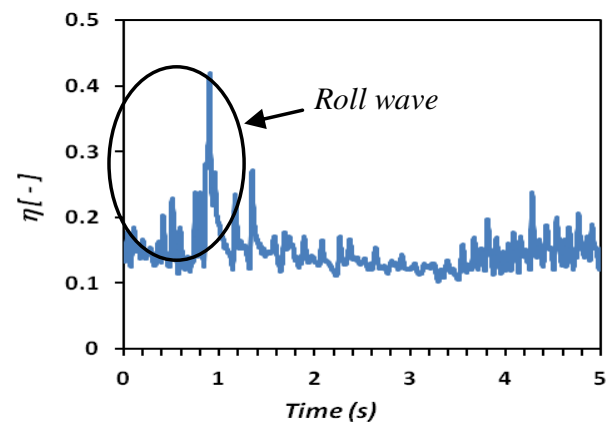

\section{Gambar 9. Contoh Liquid Hold- Up Aliran Stratified Wavy + Roll $\left(\mathrm{J}_{\mathrm{L}}=0,047 \mathrm{~m} / \mathrm{s}\right.$ $\operatorname{dan} \mathbf{J}_{\mathbf{G}}=3.77 \mathrm{~m} / \mathrm{s}$ )}

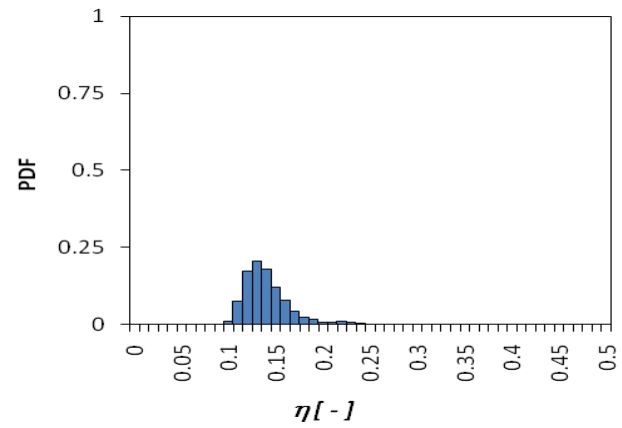

Gambar 10. Contoh PDF Aliran Stratified Wavy + Roll $\left(\mathrm{J}_{\mathrm{L}}=0,047 \mathrm{~m} / \mathrm{s}\right.$ dan $\left.\mathbf{J}_{\mathrm{G}}=3.77 \mathrm{~m} / \mathrm{s}\right)$

d. Pseudo Slug (PS)

Pola aliran ini hampir mirip dengan pola aliran stratified wavy + roll, penambahan kecepatan superfisial air pada pola aliran stratified wavy + roll akan menyebabkan terjadinya hidraulic jump 
yang oleh Lin dan Hanratty (1987) dikategorikan pseudo-slug, dimana gelombang cairan menyentuh bagian atas kemudian cairan pecah menjadi droplet sehingga secara visual menyerupai slug akan tetapi belum terjadi blockage seperti terlihat pada gambar 11 .

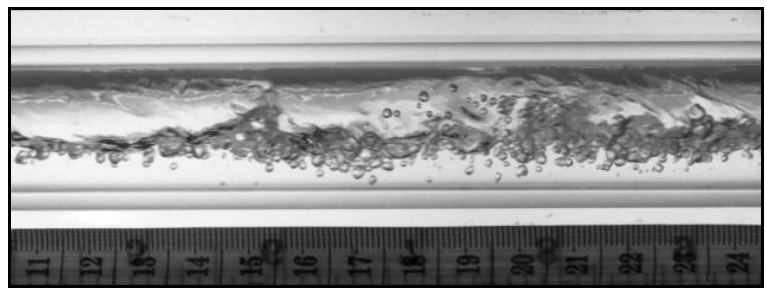

Gambar 11. Contoh Visualisasi Pola Aliran Pseudo-Slug $\left(\mathrm{J}_{\mathrm{L}}=0,092 \mathrm{~m} / \mathrm{s}\right.$ dan $\left.\mathrm{J}_{\mathrm{G}}=3.77 \mathrm{~m} / \mathrm{s}\right)$

Pola aliran pseudo-slug dapat juga dilihat dari karakteristik transien liquid hold-up seperti terlihat pada gambar 12. Sedangkan gambar 13. merupakan karakteristik probability distribution function (PDF) aliran pseudo-slug $\left(\mathrm{J}_{\mathrm{L}}=0,092 \mathrm{~m} / \mathrm{s}\right.$ dan $\left.\mathrm{J}_{\mathrm{G}}=3.77 \mathrm{~m} / \mathrm{s}\right)$.

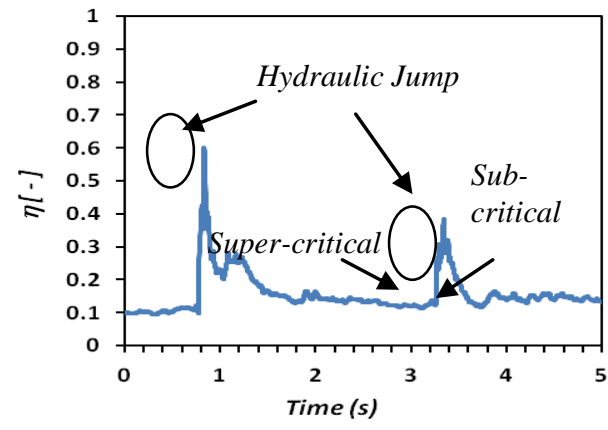

Gambar 12. Contoh Liquid Hold-Up Pola Aliran Pseudo-Slug $\left(\mathrm{J}_{\mathrm{L}}=0,092 \mathrm{~m} / \mathrm{s}\right.$ dan $\mathbf{J}_{\mathrm{G}}=3.77$ $\mathbf{m} / \mathbf{s})$

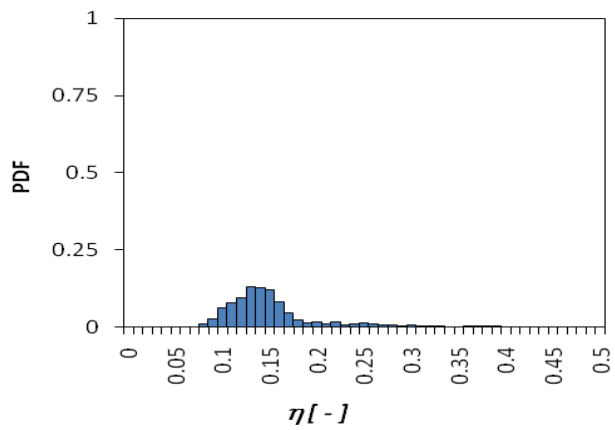

Gambar 13. Contoh PDF Pola Aliran Pseudo-Slug $\left(\mathrm{J}_{\mathrm{L}}=0,092 \mathrm{~m} / \mathrm{s}\right.$ dan $\left.\mathrm{J}_{\mathrm{G}}=3.77 \mathrm{~m} / \mathrm{s}\right)$

Pada kondisi ini jika pengaruh penambahan kecepatan superfisial air lebih dominan terhadap penambahan kecepatan superfisial udara maka pola aliran akan berubah menjadi aliran slug. Sedangkan jika pengaruh penambahan kecepatan superfisial udara lebih dominan terhadap penambahan kecepatan superfisial air maka pola aliran akan berubah menjadi aliran annular.

\subsection{Perbandingan dengan Peta Pola Aliran Lain}

Pada penelitian ini pola aliran yang diamati dibandingkan dengan peta pola aliran yang sudah ada sebagai bahan referensi. Peta pola aliran yang digunakan adalah peta pola aliran Mandhane (1974), 
Taitel dan Dukler (1976), serta Spedding dan Nguyen (1979). Peta pola aliran jenis ini dipilih sebagai bahan referensi karena sering digunakan sebagai acuan untuk penelitian tentang aliran dua fase pipa horisontal.

Pola aliran yang diamati dalam penelitian ini jika dibandingkan dengan peta pola aliran Mandhane (1974), serta Taitel dan Dukler (1976) pada gambar 14. menunjukkan ada penyimpangan pola, dimana transisi dari stratified smooth ke stratified wavy pada penelitian ini terlihat lebih bergeser ke kiri dibandingkan dengan prediksi peta Mandhane (1974), serta Taitel dan Dukler (1976). Hal ini disebabkan karena peta pola aliran Mandhane (1974), serta Taitel dan Dukler (1976) lebih bersifat umum.

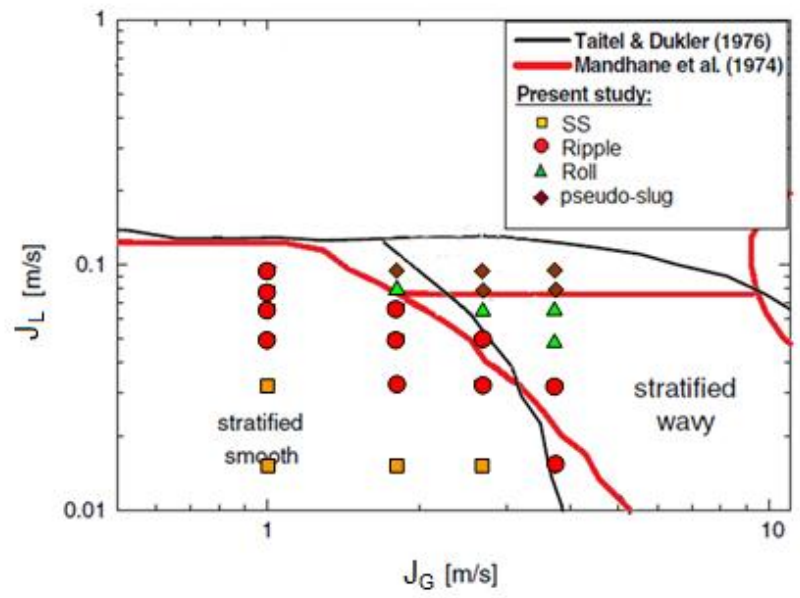

\section{Gambar 14. Perbandingan Data Penelitian \\ Dengan Peta Pola Aliran Mandhane (1974) Serta Taitel Dan Dukler (1976)}

Sedangkan Pola aliran yang diamati dalam penelitian ini jika dibandingkan dengan peta pola aliran Spedding dan Nguyen (1979) dapat dilihat pada gambar 15. Pada gambar 15. terlihat bahwa ada ketidakcocokan pola yang terjadi, dimana pola pseudo-slug terletak pada daerah STR + Roll wave pada peta Spedding dan Nguyen (1979). Hal ini disebabkan karena diameter pipa yang dipakai dalam penelitian ini $(\varnothing \mathrm{in}=2,6 \mathrm{~cm})$ lebih kecil dibanding pipa yang dipakai dalam penelitian Spedding dan Nguyen $(\varnothing \mathrm{in}=4.55 \mathrm{~cm})$, akan tetapi sebagian besar pola aliran yang diamati dalam penelitian ini sesuai dengan peta pola aliran Spedding dan Nguyen (1979).

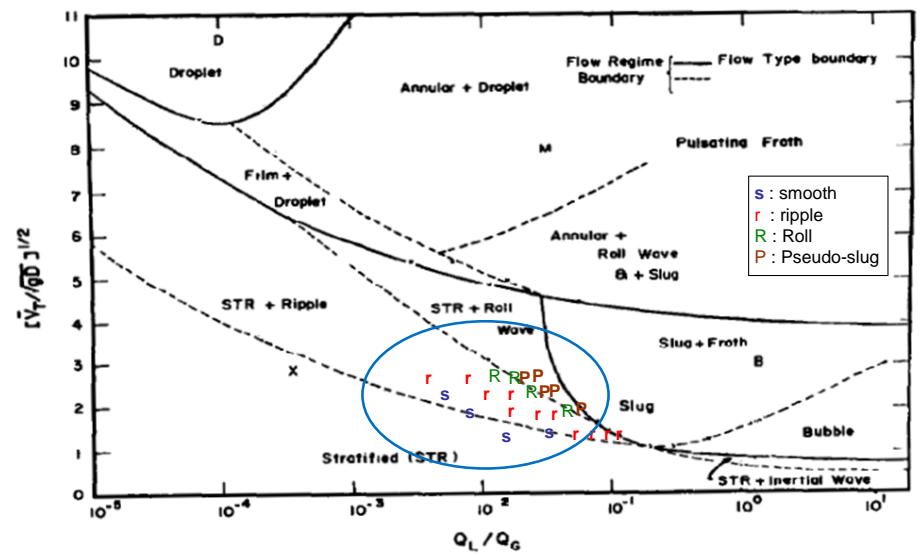

Gambar 15. Perbandingan Data Penelitian Dengan Peta Pola Aliran Spedding dan Nguyen (1979) 


\section{KESIMPULAN}

Pola aliran stratified secara detail pada penelitian ini telah berhasil diidentifikasikan dengan jelas baik secara visual maupun melalui sinyal liquid hold-up dari hasil keluaran sensor CECM. Pola ini meliputi stratified smooth (SS), stratified wavy + ripple (SR), Stratified wavy + Roll (SRW), dan Pseudo-slug (PS).

Pola aliran yang diamati dalam penelitian ini jika dibandingkan dengan peta pola aliran Mandhane (1974), serta Taitel dan Dukler (1976) pada gambar 14. menunjukkan ada penyimpangan batas transisi antara stratified smooth dan stratified wavy. Pada penelitian ini terlihat batas transisi lebih bergeser ke kiri dibandingkan dengan prediksi peta Mandhane (1974), serta Taitel dan Dukler (1976). Sedangkan jika dibandingkan dengan peta pola aliran Spedding dan Nguyen (1979) terlihat bahwa ada ketidakcocokan pola yang terjadi, dimana pola pseudo-slug terletak pada daerah STR + Roll wave pada peta Spedding dan Nguyen (1979), namun sebagian besar pola aliran yang diamati pada penelitian ini sesuai dengan peta pola aliran Spedding dan Nguyen (1979).

\section{DAFTAR PUSTAKA}

[1] Baker, O. 1954. Design of Pipelines for Simultaneous Flow of Oil and Gas, Oil and Gas J., July, pp.26

[2] Fukano, T., Measurement of time varying thickness of liquid film flowing with high speed gas flow by a constant electric current method (CECM), Nuclear Engineering and Design, pp. 363377(1998).

[3] Lin, P.Y. and Hanratty, T.J., 1986, Prediction of the initiation of slugs with linear stability theory, Int. J. Multiphase Flow, Vol. 12, pp. 19-98.

[4] Lin, P.Y. and Hanratty, T.J., 1987, Effect of Pipe Diameter on flow patterns for air-water flow in horizontal. Int. J. Multiphase Flow, Vol. 13, No. 4 ,pp. 549-563.

[5] Mandhane, J.M., Gregory, G.A., Aziz, K., 1974, A flow pattern map for gas-liquid flow in horizontal and inclined pipes, International Journal of Multiphase Flow 1 pp. 537-553.

[6] Spedding, P. L. and Nguyen, V.T., 1979, Regime Map for Air Water Two-Phase Flow, Chemical Engineering Science Vol 35, pp. 779-793

[7] Spedding, P. L. and D.R. Spence, 1993, Flow Regimes in Two-Phase Gas-liquid Flow, Int. J. of Multiphase Flow, Vol. 19, No. 2, pp. 217-225

[8[ Taitel, Y. and Dukler, A.E., 1976, A model for predicting flow regime transitions in horizontal and near horizontal gas-liquid flow, AIChE J., Vol. 22, pp. 47-55 